\title{
Pneumonia or tuberculosis? A case report in a teenage girl
}

\author{
Paweł Zapolnik' ${ }^{1}$ Andrzej Pogorzelski², Beata Zapolnik ${ }^{3}$ \\ 'Students' Scientific Association of Clinical Genetics, Department of Clinical Genetics, Medical College, University of Rzeszów \\ Rzeszów, Poland \\ 2Department of Pneumology and Cystic Fibrosis, Institute of Tuberculosis and Lung Diseases, Rabka-Zdrój, Poland \\ ${ }^{3}$ Department of Allergology and Cystic Fibrosis, Clinical Regional Hospital No. 2 in Rzeszów, Rzeszów, Poland
}

\section{ABSTRACT}

Tuberculosis (TB) is still a common infectious disease worldwide. In 2018, seven million new cases of TB were reported to the World Health Organization. The diagnosis of TB in children is difficult due to non-characteristic symptoms. A 14-year-old girl presented to a general practitioner due to coughing and general weakness for three weeks. Physical examination revealed a reduction in vesicular murmur over a significant area of the right lung, and chest X-ray showed extensive densities in the right lung. After several days of hospitalisation and antibiotic therapy for bacterial pneumonia, the girl was diagnosed with TB. A treatment plan was applied for six months. Radiological and clinical improvement was observed after the therapy. A detailed history, determining contact with the TB patient, physical examination, results of additional tests, and broad-spectrum antibiotics response are essential for diagnosis.

\section{KEY WORDS:}

children, tuberculosis, pneumonia.

\section{INTRODUCTION}

Despite the era of vaccines and antibiotics, tuberculosis (TB) is still a common health problem worldwide. In 2018, seven million new cases of TB were reported to the World Health Organization (WHO). There were 1.4 million TB deaths among people around the world in 2018 [1]. In 2018, a total of $5487 \mathrm{~TB}$ cases were reported in Poland, of which childhood TB (0-14 years) comprised $52(0.9 \%)$, including only 35 new cases of pulmonary TB [2]. The diagnosis of TB in children is difficult, due to non-characteristic symptoms, often suggesting other disease entities [3]. The aim of the study is to present an unusual case of TB imitating typical pneumonia, and to draw attention to the need to include TB in the differential diagnosis of lung diseases in children.

\section{CASE REPORT}

A 14-year-old girl presented to a general practitioner due to coughing and general weakness for three weeks. Physical examination revealed a reduction in vesicular murmur over a significant area of the right lung. The girl was directed to the children's ward of the district hospital, where a chest X-ray showed extensive densities in the right lung (Fig. 1). A chest ultrasound examination showed a hypoechogenic area between the fourth intercostal space and the diaphragm over the right lung. Her C-reactive protein (CRP) level was $49.9 \mathrm{mg} / \mathrm{l}$ (normal range: 0.0-5.0). The patient was treated with cefuroxime and clarithromycin. After nine days of combined antibiotic therapy, the CRP level decreased twice. She felt improvement, but the radiological and auscultatory changes continued (Fig. 2).

\section{ADDRESS FOR CORRESPONDENCE:}

Paweł Zapolnik, Students' Scientific Association of Clinical Genetics, Department of Clinical Genetics,

Medical College, University of Rzeszów, 1A Warzywna St., 35-310 Rzeszów, Poland,

ORCID: 0000-0001-9935-472X, e-mail: pawel.zapolnik@onet.pl 


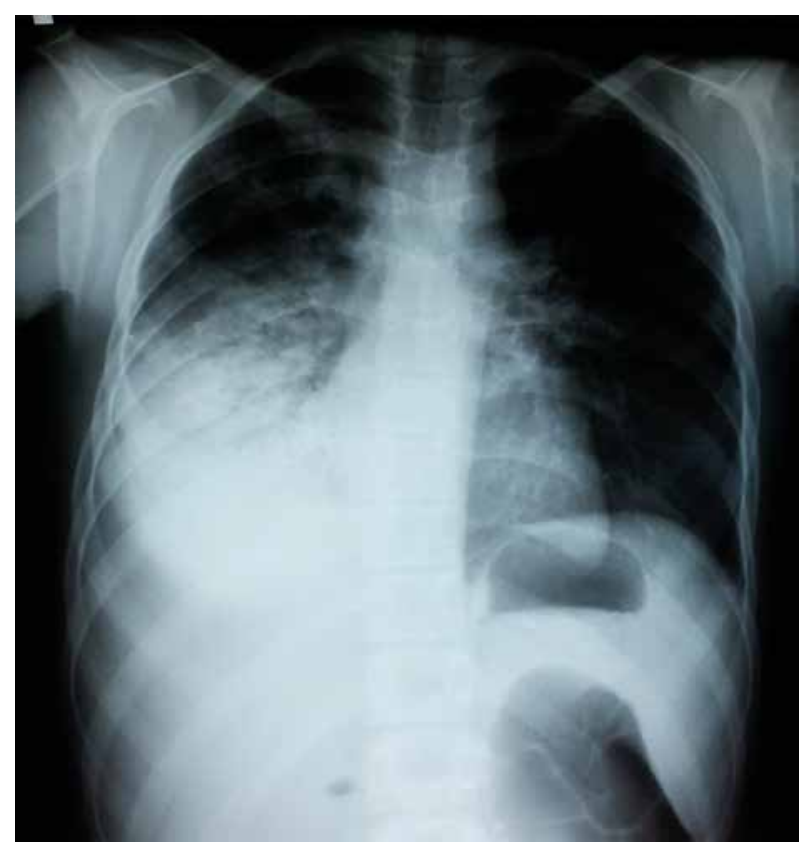

FIGURE 1. Chest X-ray at admission to the hospital

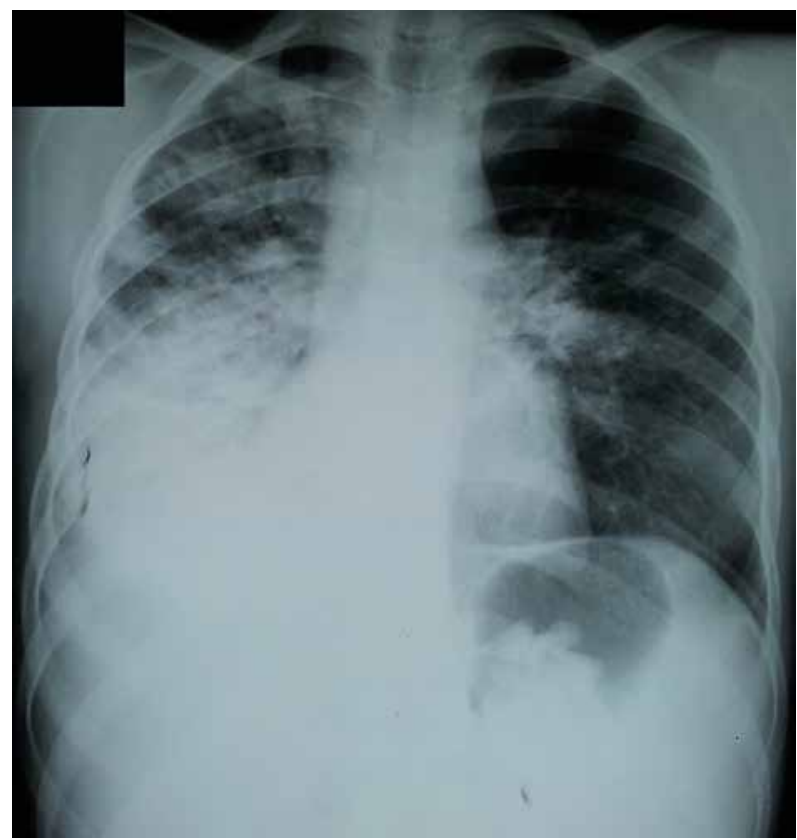

FIGURE 3. Progression of the lung changes after 10 days of extended antibiotic therapy

The patient was transferred to a hospital with a paediatric pulmonology ward, where the antibiotic therapy was extended. The girl received ceftriaxone and metronidazole. As a supportive treatment, a nebulisation with fenoterol and ipratropium was also implemented. Despite another 10 days of the therapy, progression of the changes was observed on chest X-ray (Fig. 3).

During the hospitalisation, despite the fact that the girl's parents denied the possibility of contact with a person with $\mathrm{TB}$, diagnostics for $\mathrm{TB}$ were implemented - the result of interferon $\gamma$ release assay (IGRA) and tuberculin sensitivity test was positive (skin infiltration of $14 \mathrm{~mm}$ ),

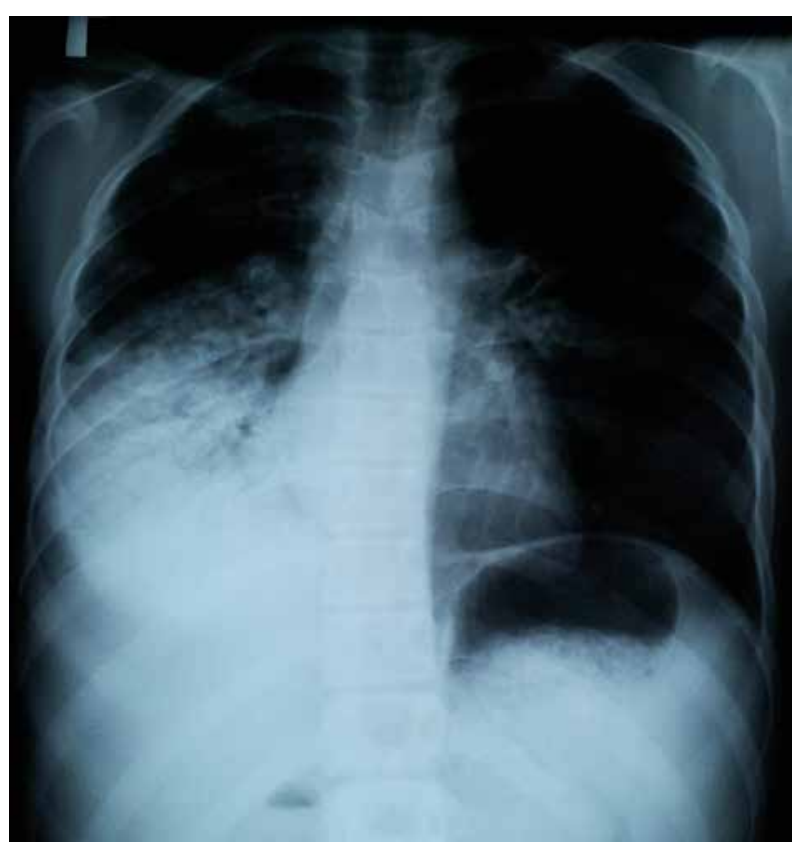

FIGURE 2. Chest X-ray after 9 days of combined antibiotic therapy

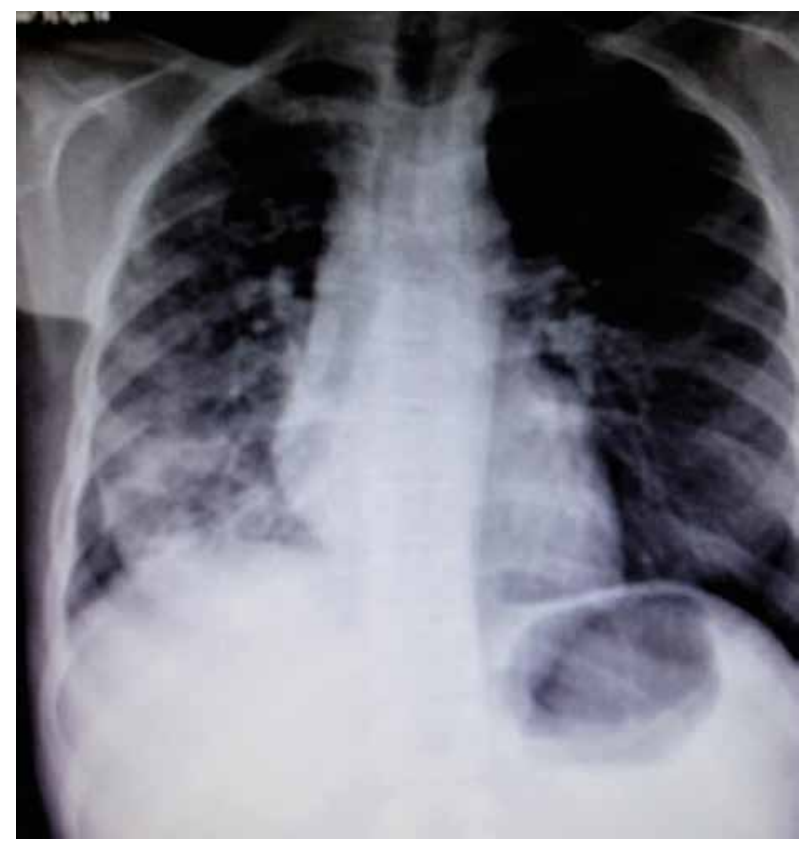

FIGURE 4. Chest X-ray after 2 months of anti-TB therapy

a microscopic examination of sputum revealed no mycobacteria. After diagnosis, the girl was transferred to a specialised centre of lung diseases.

Bronchoscopy revealed no pathological changes, but the cytologic examination of bronchoalveolar lavage fluid showed noticeable inflammation. Mycobacterium tuberculosis complex growth was confirmed in culture. A fourdrug treatment plan (isoniazid, rifampicin, ethambutol, pyrazinamide) was applied for two months. Isoniazid and rifampicin were maintained for another four months. Regression of lung changes and general condition improvement was observed after the therapy (Figs. 4 and 5). The 
girl gained weight, tolerated physical exercise well, and attended physical education classes. As a result of widening the diagnosis, the girl's father was diagnosed with active TB and treated for six months.

\section{DISCUSSION}

About 1.7 billion people are estimated to have a latent TB infection. However, only $5-10 \%$ of this group will develop TB disease during their lifetime [1]. Latent $\mathrm{TB}$ is associated with an enhanced cytotoxic response, which is mostly mediated by CD16 molecule and natural killer cells (NK cells), and continuous inflammation [4]. The aetiological factor of the diseases is a mycobacterium belonging to the Mycobacterium tuberculosis complex group. The infection is transmitted via the droplet route, and children are most often infected by adult family members [5]. After inhalation of mycobacteria to alveoli, nonspecific immune mechanisms can completely eliminate the bacteria, or the infection might develop to the primary complex, known as Ghon's complex, which is usually located in either the lower part of the upper lobe or the upper part of the lower lobe. It can also be located subpleurally. Mycobacteria can get into the nearest lymph nodes with lymphatic vessels, and then through the bloodstream to other organs $[3,5]$. In the presented case, the primary lesion was not found, and the disease had taken the form of typical pneumonia with nonspecific clinical features.

Tuberculosis might manifest in an unusual way and imitate other lung disease entities. Mascarenhas et al. [6] reported an unusual case of a giant tuberculoma in an adolescent. A 13-year-old girl had in her chest a large cystic lesion that was initially treated as a hydatid cyst. After confirming the TB diagnosis, the lesion was excisable, and the girl was treated with anti-TB agents for nine months, and the overall effect of the therapy was positive. In some cases, pulmonary TB lesions can develop from primary enlarged lymph nodes. Mirchandani et al. [7] described a case of hilar and paratracheal lymph nodes that enlarged and started lobar pneumonia with consolidations and atelectasis. Tuberculosis can also take the form of necrotising pneumonia (NP) with lung parenchymal destruction, pleural effusion, and cystic lung lesions. Jacobs et al. [8] analysed a case series of necrotising pneumonia in children in South Africa. Eight (25\%) patients out of 32 had M. tuberculosis-associated NP. There was no difference in the clinical presentation of NP caused by M. tuberculosis and other bacteria.

In the discussed case, the girl manifested non-characteristic symptoms: coughing and general weakness for three weeks, but attention was drawn by the fact that these symptoms were inadequate for the radiological changes. Clinical presentation, elevated inflammatory markers, and chest X-ray changes suggested a diagnosis

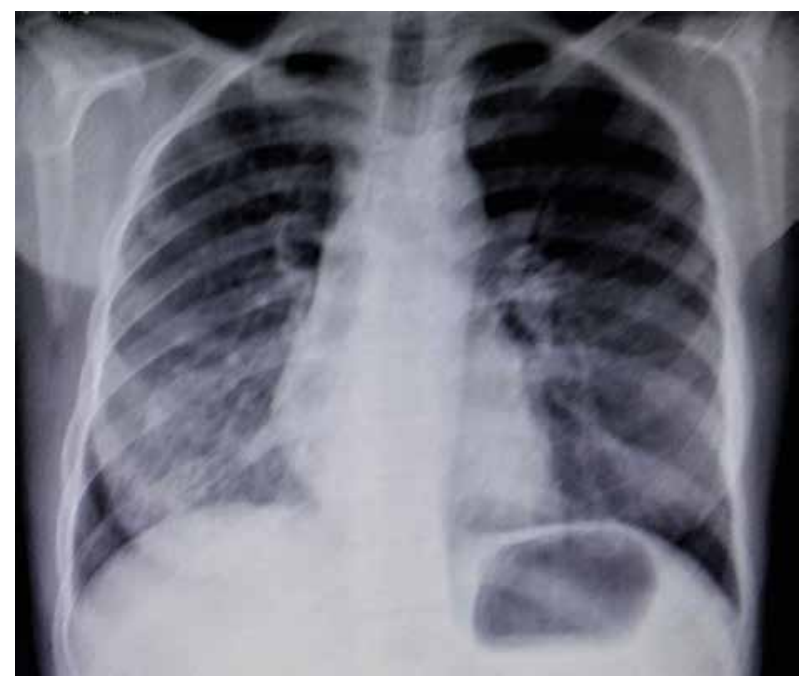

FIGURE 5. Chest X-ray at the end of the anti-TB therapy (after 6 months)

of pneumonia and resulted in the implementation of typical first-line treatment. Persistence of auscultatory and radiological changes, despite the modification of antibiotic therapy and subjective improvement felt by the patient, prompted doctors to suspect pulmonary TB. The implementation of a standard four-drug treatment for two months then a two-drug therapy for four months, resulted in complete regression of the lesions.

Diagnosis of TB in children is very difficult, especially when it comes to microbiological confirmation. Early morning gastric lavage is the preferred sample for the diagnosis of pulmonary TB in children younger than six years. In older children, it is recommended that a sputum sample be obtained [9]. Sometimes definitive bacteriological confirmation of the disease might not be possible because of the difficulties with proper collection of the material for analysis; hence, a thorough history, determining exposure to the TB patient, physical examination, results of interferon $\gamma$ release assay and tuberculin sensitivity test, imaging, such as chest X-ray and high-resolution computed tomography (HRCT), and broad-spectrum antibiotics response are very important for making the correct diagnosis $[5,10]$.

\section{CONCLUSIONS}

Tuberculosis should be considered in the differential diagnosis of respiratory diseases in children. This, seemingly forgotten disease often becomes a real challenge for doctors. A detailed history, determining contact with TB patients, physical examination, results of IGRA and tuberculin sensitivity test, imaging, and broad-spectrum antibiotics response are essential for a correct diagnosis.

\section{DISCLOSURE}

The authors declare no conflict of interest. 


\section{REFERENCES}

1. World Health Organization. Global tuberculosis report 2019. World Health Organization, Geneva 2019.

2. Korzeniewska-Koseła M. Gruźlica i choroby układu oddechowego w Polsce w 2018 r. Instytut Gruźlicy i Chorób Płuc, Warszawa 2019.

3. Kosińska J, Górski P, Grzelewska-Rzymowska I. Gruźlica u dzieci od diagnostyki do chemioprofilaktyki i leczenia. Pediatr Med Rodz 2014; 10: 111-127.

4. Chowdhury RR, Vallania F, Yang Q, et al. A multi-cohort study of the immune factors associated with $\mathrm{M}$. tuberculosis infection outcomes. Nature 2018; 560: 644-648.

5. Bielecka T. Gruźlica. In: Kulus M, Krenke K. Pulmonologia dziecięca. PZWL Wydawnictwo Lekarskie, Warszawa 2018: 249-279.

6. Mascarenhas MI, Pacheco S, Silvestre C, et al. Giant tuberculoma in an adolescent: atypical form of tuberculosis. BMJ Case Rep 2012; 2012: bcr2012006872.

7. Mirchandani LV, Kamath SS, Kutty JT, Iyer A. Epituberculosis Revisited: Case Report and Review. J Clin Diagn Res 2017; 11: OD05-OD07.

8. Jacobs C, Goussard P, Gie RP. Mycobacterium tuberculosis, a cause of necrotising pneumonia in childhood: a case series. Int J Tuberc Lung Dis 2018;22: 614-616.

9. Velayati AA. Tuberculosis in children. Int J Mycobacteriol 2016; 5 (Suppl 1): S1-S2.

10. Augustynowicz-Kopeć E, Demkow U, Grzelewska-Rzymowska I, et al. Guidelines of Polish Respiratory Society concerning diagnosis, treatment and prevention of tuberculosis in adults and in children. Pneumonol Alergol Pol 2013; 81: 323-379. 